This article was downloaded by: [University of Calgary]

On: 09 January 2012, At: 15:23

Publisher: Routledge

Informa Ltd Registered in England and Wales Registered Number: 1072954 Registered office: Mortimer House, 37-41 Mortimer Street, London W1T 3J H, UK

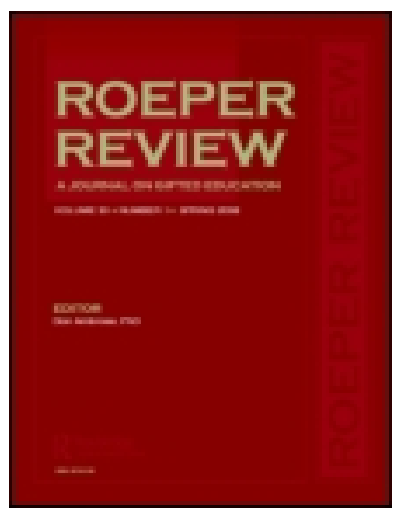

\title{
Roeper Review
}

Publication details, including instructions for authors and subscription information: http:// www. tandfonline.com/loi/ uror20

\section{Sensitivity among gifted persons: A multi\#faceted perspective}

\author{
Sal Mendaglio ${ }^{\text {a }}$ \\ Available online: $20 \mathrm{~J}$ an 2010
}

${ }^{a}$ Associate professor and chair of the counseling psychology program, Department of Educational Psychology, University of Calgary, Alberta, Canada

To cite this article: Sal Mendaglio (1995): Sensitivity among gifted persons: A multi \#faceted perspective, Roeper Review, 17:3, 169-172

To link to this article: http:// dx. doi. org/ 10.1080/02783199509553652

\section{PLEASE SCROLL DOWN FOR ARTICLE}

Full terms and conditions of use: http://www.tandfonline.com/page/terms-and-conditions

This article may be used for research, teaching, and private study purposes. Any substantial or systematic reproduction, redistribution, reselling, loan, sub-licensing, systematic supply, or distribution in any form to anyone is expressly forbidden.

The publisher does not give any warranty express or implied or make any representation that the contents will be complete or accurate or up to date. The accuracy of any instructions, formulae, and drug doses should be independently verified with primary sources. The publisher shall not be liable for any loss, actions, claims, proceedings, demand, or costs or damages whatsoever or howsoever caused arising directly or indirectly in connection with or arising out of the use of this material. 


\section{Sensitivity Among Gifted Persons: A Multi-faceted Perspective}

\section{Sal Mendaglio}

Several interrelated themes arise out of recent literafure on sensitivity as an affective characteristic of gifted persons. A multifaceted approach to sensitivity is proposed which conceptualizes sensitivity as consisting of cognitive, affective, interpersonal and intrapersonal dimensions. Four psychological concepts, self-awareness, perspective-taking emotional experience, and empathy are used to elaborate upon a definition of sensitivity.

Sal Mendaglio is an associate professor and chair of the counseling psychology program, Department of Educational Psychology, University of Calgary, Alberta, Canada. His interests in giftedness lie in counseling, emotionality, and self-concept.

$\mathrm{T}$ The importance of the non-cognitive aspects of giftedness has long been recognized. Galton noted that emotional interest, in addition to high intellect, was needed for outstanding achievement (Stein, 1986). He also believed that mental activity consisted of thinking, feeling and willing (Stein, 1986 , p. liv). Other evidence regarding the importance of the non-cognitive aspects of giftedness are found in the writings of the early part of this century (e.g. Davis, 1924; Hollingworth, 1926). A more recent illustration of this emphasis is the appearance of references to affective characteristics in textbooks as well as journal articles. Enhanced sensitivity and intensity are two of the affective characteristics that address the emotionality of giftedness. Not all of the affective characteristics are so focused on emotion.

Acknowledgement of the importance of the affective dimension of gifted persons is certainly not restricted to writers and researchers in gifted education. Educators, parents, and counsellors who have experience with gifted children and adolescents are very well acquainted with the challenges involved in coping with emotionality in them. The commonly accepted wisdom is that gifted persons feel more because they see more than their nongifted counterparts. As a psychologist interested in the emotions of gifted persons, the author's primary interest with respect to characteristics of gifted persons rests with emotional intensity and sensitivity.

The purpose of this article is to propose a conception of sensitivity which is a synthesis of emergent themes in the literature seen through the lens of the author's counseling experience with gifted students, their families, and teachers. In addition, established psychological concepts are used to further elaborate on the meaning of sensitivity.

\section{Affective Characteristics}

Not all of the characteristics noted as affective pertain directly to emotionality in gifted persons. This statement is reflective of the author's bias rather than a criticism. Psychologists associate affective with emotional, and from that point of view, sensitivity is an affective characteristic, while a characteristic like leadership is not (Mendaglio, 1993).

The following review of literature presents exemplars of how the field views this area. In addition to sensitivity and intensity, Clark (1988), lists the following affective characteristics: knowledge about emotions, sense of humour, idealism and a sense of justice, high expectations of self and others, strong need for consistency between values and actions; and advanced moral judgment. Although she does not categorize them as such, of the traits listed by Lovecky (1992), sensitivity, excitability and entelechy would be affective characteristics. For Baska (1989), these include: aesthetic sensitivity, sense of justice, altruism and idealism, sense of humour, emotional intensity, early concern about death, perfectionism, high levels of energy, strong attachments and commitments. Franks \& Dolan (1982) present yet another view of affective characteristics: persistence, independence, and self-concept.

\section{Descriptions of Sensitivity}

Clark (1988) actually refers to two types of sensitivities: unusual sensitivity to the expectations and feelings of others; and, sensitivity to inconsistency between ideals and behaviour. In this latter usage, it appears from the context that Clark refers to being aware of inconsistencies within self as well as others (p. 260). In Clark's succinct description of sensitivity, the complexity of sensitivity can be inferred. Far from being a simple, unitary concept, sensitivity is a complex process which focuses on both the emotional and cognitive domains, and on self and others. This complexity is further reinforced in other descriptions of sensitivity.

In Baska's (1989) list of affective characteristics, we also see two references to sensitivity, one direct and one indirect: aesthetic sensitivity and emotional intensity. Aesthetic sensitivity refers to a manifestation of the gifted child's appreciation for complexity with particular reference to works of art. Baska reserves this affective characteristic for depicting the child's ability to interpret works of art. Thus works of art are "surprisingly comprehensible to young gifted children" (Baska, p. 23).

Emotional intensity is presented as a mixture of intensity and sensitivity. Gifted children are said to experience emotional reactions at a deeper level than their age peers. They are also described as being sensitive to nuance of expression and use of language. Sensitivity for Baska includes an ability to be aware of subtleties in interpersonal communication, and to apprehend complexity at a young age. Hypersensitivity is also used though no elaboration is provided on its meaning.

R aska's depiction seems to Bemphasize the more cognitive domain. Interpretation of complex art works and awareness of the subtleties of interpersonal communication points are emphasized in her description. It may very well be that the affective aspects are included in the word "hypersensitivity."

The reference to sensitivity in a discussion of emotional intensity also illustrates some of the complexities of dealing with sensitivity as a distinct affective characteristic. Intensity and sensitivity are related concepts, yet both in the area of gifted education and elsewhere (Larsen \& Diener, 1987) such a distinction is made.

Manuscript submitted March, 1994 Revision accepted August, 1994. 
W hile Baska treats sensitivity in part under emotional intensity, Lovecky (1992) includes intensity in her description of sensitivity. In her view, sensitivity is one of the five traits associated with gifted individuals. For Lovecky (1992, p. 21), the trait of sensitivity is characterized by a "depth of feeling that results in a sense of identification with others (people, animals, nature, the universe)." Passion, compassion, and empathy are associated with sensitivity, with passion being the central aspect of sensitivity. Passion is depth of feeling which results in a rich, complex, intense emotional life for these persons. Passionate people are said to "think with their feelings," since they form deep attachments and react to the feeling tone of a situation. She also notes that passion refers to an intense commitment to both people and ideas.

Lovecky states that "Sensitive and compassionate children are highly empathic." (1992, p.39). Compassion refers to a sense of caring for others which facilitates the making of commitments to social causes. This is motivated by a wish to reduce the pain of others. A high degree of empathy is associated with compassion and, by inference, not associated with passion. Empathy refers to the person's actually experiencing the feelings of another and not simply knowing or inferring those feelings. Difficulties may arise out of this process. For example, such empathizing may lead the gifted person to believe that the other's feelings are actually one's own.

The inclusion of empathy in a discussion of sensitivity seems very appropriate. However, it adds a whole new dimension. With the use of empathy comes the variety of definitions writers use. Lovecky emphasizes the experiencing of another's emotions as empathy. For others (Roeper, 1982; Silverman, 1993b) the use of the term includes some form of altruistic behaviour.

Roeper (1982) uses empathy to refer to the gifted individual's heightened sensitivity to the emotions of others and a sense of compassion. Roeper (1982) has long argued for greater attention to the emotional area. She believes that there is sufficient evidence to indicate that some gifted are enormously empathic and that such persons demonstrate an emotional giftedness. Her convictions regarding the centrality of sensitivity are reflected in her definition of gifted: "Giftedness is a greater awareness, a greater sensitivity, and a greater ability to understand and transform perceptions into intellectual and emotional experiences" (Roeper, 1982, p. 21). Her aim in this statement is not to define sensitivity and so the meaning of the word is not specified. However, Roeper is explicit regarding her use of empathy which refers to emotional sensitivity in one's dealings with others. She illustrates by describing how a gifted young chess player lost his interest in winning a match when he noticed tears in his opponent's eyes.

Both Piechowski (1991) and Silverman (1993a) draw on Dabrowski's Theory of Positive Disintegration (Dabrowski \& Piechowski, 1977) to discuss the emotional aspects of giftedness. In Dabrowski's theory, overexcitability is a central concept. The idea of overexcitability is analogous to the notion of intensity. Piechowski (1991), along with many of those who speak of affective characteristics e.g., (Clark, 1988) distinguishes between emotional intensity and emotional sensitivity. In general, he believes that intensity refers to the depth of experience of emotions. For

Piechowski, emotional sensitivity has several facets: sensitivity to feelings of others, to feelings in self, and sensitivity to injustice.

Qilverman (1993b) also distin$\checkmark$ guishes sensitivity from intensity. She associates the latter with a passion for learning. Consistent with her Dabrowskian perspective, Silverman notes that intensity is associated with all of the personality and intellectual characteristics since "the overexcitabilities can be thought of as intensities" (Silverman, 1993b, p. 64). In Silverman's words, overexcitabilites "represent expanded awareness and a heightened capacity to respond to stimuli of various types" (1993a, p. 13). Five overexcitabilites are evident: psychomotor, sensual, imaginational, intellectual, and emotional. A detailed presentation is beyond the scope of this article. However, it is important to note that emotional overexcitability is viewed as essential for advanced development. Emotional overexcitability is described as "the capacity for emotional depth, attachment to people and animals, intensity, sensitivity, empathy, self-criticism, inhibition, fears, guilt, and anxiety" (Silverman, 1993a, p. 16). Thus, it subsumes concepts that are associated with sensitivity as an affective characteristic.

In Silverman's (1993b) view, sensitivity and empathy are expressions of emotional overexcitability. While sensitivity and empathy are seen as related concepts, they do not necessarily occur together. That is, some gifted children may be sensitive and not empathic. Inferring from some clinical vignettes she presents, Silverman seems to use sensitivity to refer to children's awareness of feelings within self, while empathy refers to consciousness of feelings of others. And so a child who is extremely sensitive to criticism, whose feelings may be easily hurt, may not be characterized by empathy. However, it seems that an empathic gifted child is likely to be sensitive.

T ike Roeper (1982), Silverman

Lbelieves that there are some children who are characterized by high levels of empathy across situations. Her vignettes suggest that empathy is not simply an intellectual understanding of the feelings of others. There is a sense that empathy is reflected in a child's altruism. Empathy, then, would include both an awareness of others' feelings and an indication that this affects the child deeply and may motivate action to assist the person.

\section{Themes Regarding Sensitivity}

While we may possess an intuitive understanding of what sensitivity means, writings in the area reveal it to be a rather complicated notion. Several themes emerge.

Gifted persons are accepted as being more sensitive than their nongifted counterparts.

Awareness or perceptiveness is implicitly or explicitly described as the core of sensitivity.

Also, a person may be sensitive to both self and others. A gifted child may be easily hurt as a result of being sensitive to criticism. In this case, sensitivity implies the direction of awareness is to self. But further, the child may be able to discern the emotions of another, and even experience those emotions.

In addition to being sensitive to emotional content, persons are sensitive to cognitive content as well. Sensitivity has been used to describe gifted persons' awareness of inconsistencies between ideals and behaviour as well as being perceptive of nuances in interpersonal communication.

Sensitivity can be distinguished from intensity. Although some writers do not appear to do so, others clearly argue for the distinction. Empathy is often associated with sensitivity, however, definitions of empathy seem to vary. 


\section{Sensitivity: A Multi-faceted Perspective}

The task that the author chose was to propose a working definition of sensitivity which would: take into account the various themes evident in the literature; be faithful to his own counseling observations; and, be elaborated upon by existing appropriate psychological concepts.

For the most part, the author's experience with gifted persons corroborates the views presented. One issue which seems implicit in the views discussed above, but which must be made explicit, is the matter of experience versus expression of sensitivity. As a result of counseling experience with gifted persons, it seems that some persons who are very sensitive would never be so described by their families or teachers. Whether their sensitivity is directed toward self or others, these gifted persons-children and particularly adultsmay even be described as insensitive since they rarely, if ever, openly express their thoughts and feelings. For the purposes of defining sensitivity, it will be sitivity is not necessarily

expressed directly to others.

Gacets of sensitivity include self, other, thinking and feeling.

These are represented in Figure 1. Sensitivity is seen as both intrapersonal and interpersonal with each having a cognitive and affective aspect.

For the purposes of the following discussion of sensitivity these labels are used. Sensitivity directed at self will be called intrapersonal affective or intrapersonal cognitive sensitivity. Sensitivity directed at others will be called interpersonal affective or interpersonal cognitive sensitivity.

Psychological concepts are now used to elaborate upon the facets of sensitivity referred to in the working definition proposed above. Figure 2 is a representation of the concepts associated with each facet of sensitivity. Looking at the Cognitive aspect first, we have "selfawareness" for intrapersonal sensitivity; and "perspective-taking" for interpersonal sensitivity. For the Affective, "emotional experience" is used to designate the intrapersonal; "empathy" indicates the interpersonal.

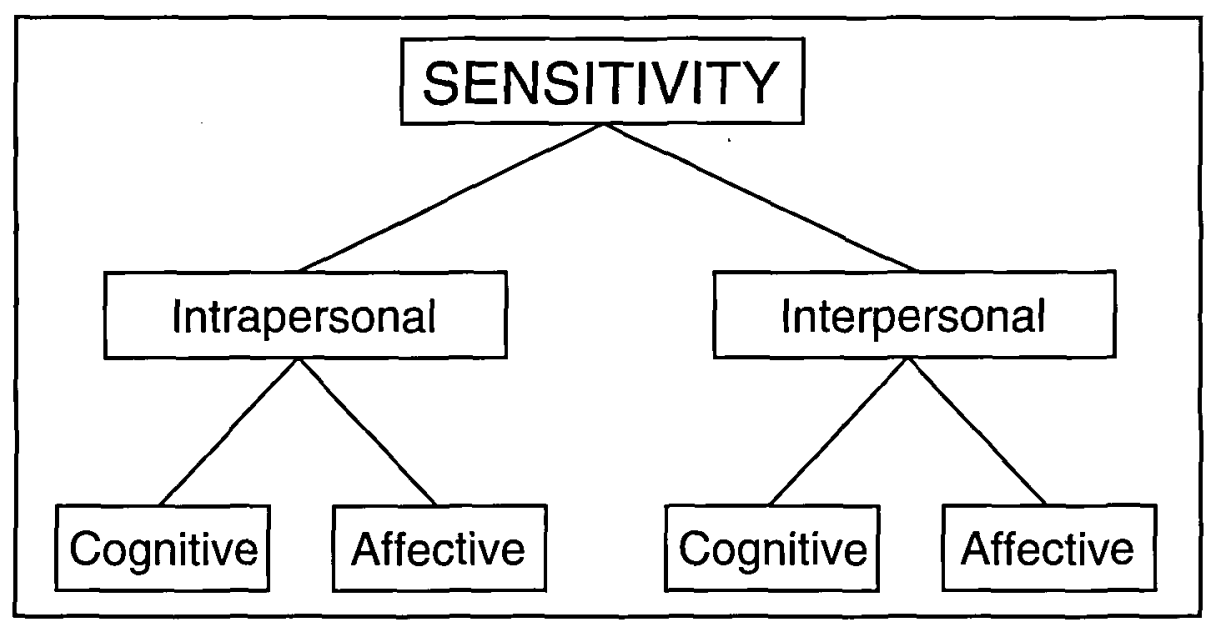

Figure 1 Components of Sensitivity

assumed that a requirement is its experience and not its expression.

The following definition of sensitivity attempts to reflect the multi-facted or multi-dimensional representation of sensitivity evident in the literature and confirmed by counseling experience.

Sensitivity refers to an awareness of one or more of the following: thoughts, feelings, and behavior of self or others. This awareness has the potential of promoting a greater understanding and/or increased emotional responsiveness to the feelings of self and others. A person's experience of sen-

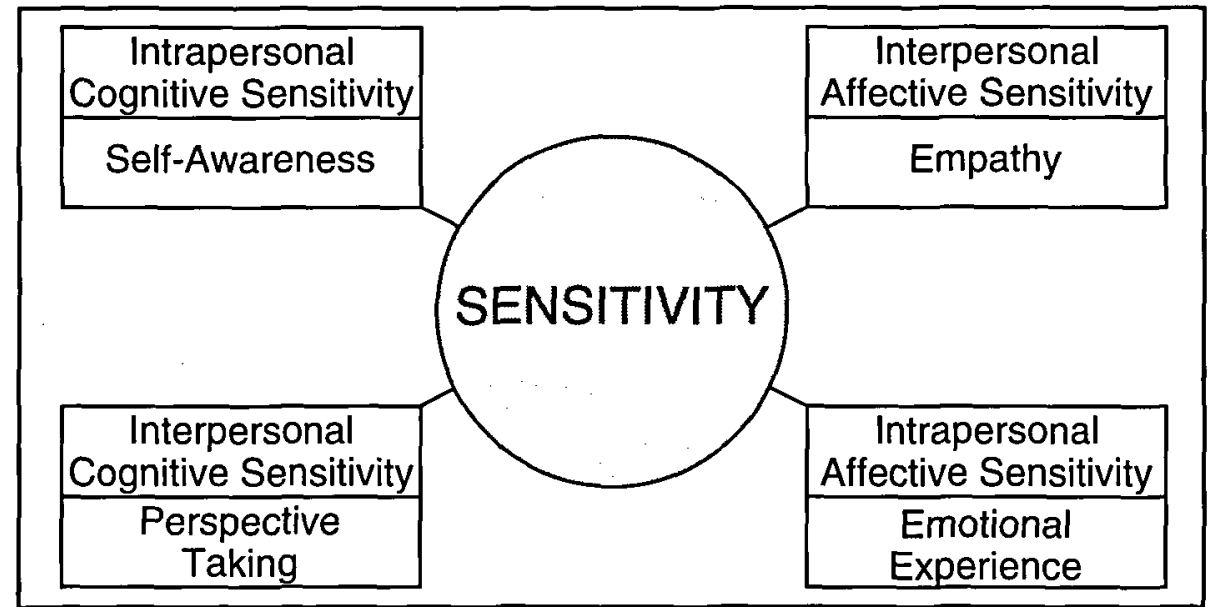

Figure 2 A multi-faceted perspective of sensitivity

\section{Intrapersonal cognitive sensitivity: self-awareness}

Self-awareness is defined in a metacognitive fashion. Metacognition refers to the awareness of one's thinking processes which is associated with a variety of matters including self-regulation (Flavell, 1979). Reflecting this perspective, an important differentiation between self-knowledge and self-awareness is made by Lewis \& Brooks-Gunn (1979). Self-knowledge includes use of self-referent statements, knowledge of how one is similar and different from others. In contrast, self awareness is "knowledge of the knowledge of self" (Lewis \& Brooks-Gunn, p. 26). Knowledge of knowledge when applied to self suggests that a person is reflecting upon self and not simply describing self. Such a view of self-awareness is expressed, for example, when sensitive gifted children are described as being painfully aware of self.

\section{Interpersonal cognitive sensitivity: perspective-taking}

Perspective-taking is a concept which has been popularized by writers and researchers in the area of social cognitive development. It refers to "an ability to imagine what other people may be thinking and feeling" (Berk, 1989). While there is reference to feelings, it is the conceptual understanding of others which is emphasized by this term.

In the course of our interactions with others, we regularly generate inferences about others' thoughts, and feelings. In applying sensitivity to gifted persons, we assume that their inferences about others' internal states are more accurate than their nongifted peers. A possible explanation may be that gifted persons are more likely to be more 
observant of others' behaviours and make better use of their observational data. For example, being tuned into the nuances of interpersonal communication, gifted individuals have more data upon which to base their inferences. Enhanced awareness of matters such as body language, tone of voice, rate of speech, facial expression in addition to the words used provides more grist for the perspective-taking mill. Being very sensitive in this context means that a person's inferences about another's internal state are more often accurate. It does not relate to experiencing of emotions. That is reserved for the concept of empathy presented later.

\section{Affective Sensitivity}

\section{Intrapersonal affective sensitivity: emotional experience}

Emotional experience is awareness of one's own emotional states (Lewis \& Michalson, 1983). In this view, emotional states are not felt by the person until attention is focused on them. Emotional experiences are the product of awareness and evaluation of bodily changes occurring during emotional states. Gifted persons are more likely to be sensitive to their emotional states since cognitive processes-awareness and evaluation-are emphasised in this interpretation of emotional experience. Being aware of one's emotions is synonymous with emotional experience. As such awareness increases, so does emotional experience.

\section{Interpersonal affective sensitivity: empathy}

Two distinct conceptions of empathy are presented here to reflect how this word is used in the literature on sensitivity in gifted persons. Empathy is seen by some researchers as a vicarious experiencing of the perceived emotional responses of another (Bryant, 1986; Eisenberg \& Strayer, 1987). The descriptor "vicarious" is used to note that the actual source of the emotion rests in the other and not the self. Lovecky's (1992) indication that some gifted children feel the emotions of another would reflect this view of empathy.

The other position on empathy arises out of counseling and psychotherapy. Carl Rogers' definition (1961) best captures this perspective on empathy. Empathy is seen as the perception of another's internal frame of reference including thoughts and feelings, as if we were that person but not losing that "as if" condition. The counseling/therapeutic approach to empathy, emphasizes the communicative aspect of the process.

That is, in using empathy we attempt to understand as fully as possible the world of another while still retaining a separation from the other. Then, we communicate that understanding to the other in an appropriate, helpful manner.

Silverman's (1993b) and Roeper's (1982) references to empathy seem to coincide with the Rogerian approach. Both writers indicate that empathy has an expressive component. The person's empathy is seen in her or his altruistic behaviour.

An important characteristic of the definition of sensitivity proposed in this article relates to expression of sensitivity. Overt expression is not considered a requirement for sensitivity. And so, while both approaches to empathy would be acceptable, it is empathy as a vicarious emotional experience that is consistent with the author's veiw of sensitivity.

\section{Conclusion}

A definition of sensitivity has been proposed. It attempts to capture some key themes in the literature as well as the author's professional experience. In the latter part of the article, concepts drawn from the field of psychology were associated with facets of sensitivity. The author's use of four distinct psychological concepts - self-awareness, perspective-taking, emotional experience, and empathy-indicates how complex sensitivity is for him. A number of yet to be resolved issues inherent in this presentation manifest this complexity.

Cognition and affect are presented in places as if they were two unrelated factors. In the Piagetian tradition it has long been acknowledged that cognition and affect are intermeshed (Piaget, 1981). This interconnectedness is seen as well in the discussion of emotional experience. Lewis \& Michalson (1983) as well as others (Lazarus, 1991) argue for the relationship between cognition and affect.

A similar interrelatedness involving self and other has been described over time in the literature. From the symbolic interactionist tradition (Mead, 1934), self is seen as emerging out of social interaction and is rooted in the connection between self and other. More recent references can be found in feminist liter- ature, as indicated by the "self in relation" concept (Calloni \& Handal, 1992). Thus, as with cognition and affect, self and other can be seen as an artificial distinction. Future elaboration of the definition of sensitivity needs to address these matters.

While there is a wealth of evidence provided from educational and psychological practice, there is no body of research on the topic of sensitivity (Piechowski, 1991). Regardless of whether there is agreement with the author's conceptualization of sensitivity, it is hoped that this presentation has drawn some further attention to this very important affective characteristic.

\section{REFERENCES}

Baska, L. K. (1989). Characteristics and needs of the gifted. In J. F. Feldhusen, J. Van Tassel-Baska, K. Seeley (Eds.), Excellence in educating the gifted (pp. 15-28). Denver: Love Publishing.

Berk, L. E. (1989). Child development. Boston: Allyn \& Bacon.

Dabrowski, K. \& Piechowski, M. M. (1977). Theory of levels of emotional development (Vols. 1 \& 2), Oceanside, NY: Dabor Science.

Bryant, B. K. (1986). An index of empathy for children and adolescent. Child Development, 53, 413-425.

Calloni, J. C., \& Handal, P. J. (1992). Differential parental attachment: Empirical support for the self-in-relation model. Perceptual and Motor Skills, 75, 903-906.

Clark, B. (1988). Growing up gifted: Developing the potential of children at home and at school (3rd ed.). New York: Macmillan.

Davis, H. (1924). Personal and social characteristics of gifted children. In G. M. Whipple (Ed), The Twentythird yearbook of the national society for the study of education (pp. 123-143). Bloomington: Public School Publishing.

Eisenberg, N., \& Strayer, J. (1987). Critical issues in the study of empathy. In N. Eisenberg \& N. Strayer, (Eds), Empathy and its development (pp. 3-16). New York: Cambridge University Press.

Flavell, J. (1979). Metacognitive aspects of problem solving. In $\mathrm{L}$. B. Resnick (Ed.), The nature of intelligence (pp. 231-235). Hillsdale, NJ: Erlbaum.

Hollingworth, L. S. (1926). Gifted children: Their nature and nurture. New York: Macmillan.

Larsen, R. J., \& Diener, E. (1987). Affective intensity as an individual difference characteristic: A review. Journal of Research in Personality, 21, 1-39.

Lazarus, R. S. (1991). Emotion and adaptation. New York: Oxford University Press.

Lewis, M., \& Brooks-Gunn, J. (1979). Social cognition and the acquisition of self. New York: Plenum.

Lewis, M., \& Michalson, L. (1983). Children's emotions and moods: Developmental theory and measurement. New York: Plenum.

Lovecky, D. V. (1992). Exploring social and emotional aspects of giftedness in children. Roeper Review, 15(1), 18-25.

Mead, G. H. (1934). Mind, self, and society. Chicago: University of Chicago Press.

Mendaglio, S, (1993) Sensitivity: Bridging affective characteristics and emotions. Journal of Secondary Gifted Education, 5(1),pp 10-13.

Piaget, J. (1981). Intelligence and affectivity: Their relationship during child development. Palo Alto: Annual Reviews Inc.

Piechowski, M. M. (1991). Emotional development and emotional giftedness. In N. Colangelo \& G. Davis (Eds.), Handbook of gifted education (pp.285-306). Needham heights: Allyn \& Bacon.

Roeper, A. (1982). How the gifted cope with their emotions. Roeper Review, 5(2), 21-24.

Rogers, C. R. (1961). On becoming a person. Boston: Houghton Mifflin.

Silverman, L. K. (1993a). Understanding giftedness. In L. $\mathrm{K}$. Silverman (Ed.), Counseling the gifted and talented (pp.3-28). Denver: Love Publishing.

Silverman, L. K. (1993b). A developmental model for counseling the gifted. In L. K. Silverman (Ed.), Counseling the gifted and talented (pp. 51-78). Denver: Love Publishing.

Stein, M. I. (1986). Gifted, talented, and creative young people. New York: Garland. 